\title{
A free weekly iron-folic acid supplementation and regular deworming program is associated with improved hemoglobin and iron status indicators in Vietnamese women
}

\author{
Gerard J Casey1, Tran Q Phuc², Lachlan MacGregor ${ }^{1,3}$, Antonio Montresor ${ }^{4}$, \\ Seema Mihrshahi ${ }^{1}$, Tran D Thach ${ }^{5}$, Nong T Tien ${ }^{6}$ and Beverley-Ann Biggs* ${ }^{*}, 7$
}

\begin{abstract}
Address: ${ }^{1}$ Department of Medicine (RMH/WH), The University of Melbourne, The Royal Melbourne Hospital, Parkville 3050, Australia, ${ }^{2}$ Department of Parasitology, National Institute of Malariology, Parasitology and Entomology (NIMPE), Hanoi, Vietnam, ${ }^{3} \mathrm{Clinical}$ Epidemiology \& Health Service Evaluation Unit, Royal Melbourne Hospital, Parkville 3050, Australia, ${ }^{4}$ Public Health Specialist, World Health Organization, Hanoi, Vietnam, ${ }^{5}$ Research And Training Centre for Community Development, 39 Lane 255, Vong St., Hanoi, Vietnam, ${ }^{6} 6$ Department of Malaria Treatment and Research, National Institute of Malariology, Parasitology and Entomology (NIMPE), Hanoi, Vietnam and ${ }^{7}$ Centre of Clinical Research Excellence in Infectious Diseases (CCREID), The Royal Melbourne Hospital, Parkville 3050, Australia

Email: Gerard J Casey - gcasey@unimelb.edu.au; Tran Q Phuc - tquangphuc@yahoo.com; Lachlan MacGregor - lachlan.macgregor@pacific.net.au; Antonio Montresor - montresora@who.int; Seema Mihrshahi - seemam@unimelb.edu.au; Tran D Thach - indthach@yahoo.com; Nong T Tien - nongthitien@yahoo.com; BeverleyAnn Biggs* - babiggs@unimelb.edu.au

* Corresponding author
\end{abstract}

Published: 24 July 2009

BMC Public Health 2009, 9:26I doi:|0.| |86/|47|-2458-9-26|
Received: 25 November 2008

Accepted: 24 July 2009

This article is available from: http://www.biomedcentral.com/I47|-2458/9/26 I

(C) 2009 Casey et al; licensee BioMed Central Ltd.

This is an Open Access article distributed under the terms of the Creative Commons Attribution License (http://creativecommons.org/licenses/by/2.0), which permits unrestricted use, distribution, and reproduction in any medium, provided the original work is properly cited.

\begin{abstract}
Background: Anemia due to iron deficiency is recognized as one of the major nutritional deficiencies in women and children in developing countries. Daily iron supplementation for pregnant women is recommended in many countries although there are few reports of these programs working efficiently or effectively. Weekly iron-folic acid supplementation (WIFS) and regular deworming treatment is recommended for non-pregnant women living in areas with high rates of anemia. Following a baseline survey to assess the prevalence of anemia, iron deficiency and soil transmitted helminth infections, we implemented a program to make WIFS and regular deworming treatment freely and universally available for all women of reproductive age in two districts of a province in northern Vietnam over a 12 month period. The impact of the program at the population level was assessed in terms of: i) change in mean hemoglobin and iron status indicators, and ii) change in the prevalence of anemia, iron deficiency and hookworm infections.
\end{abstract}

Method: Distribution of WIFS and deworming were integrated with routine health services and made available to 52,000 women. Demographic data and blood and stool samples were collected in baseline, and three and 12-month postimplementation surveys using a population-based, stratified multi-stage cluster sampling design.

Results: The mean $\mathrm{Hb}$ increased by $9.6 \mathrm{~g} / \mathrm{L}(95 \% \mathrm{Cl}, 5.7, \mathrm{I3.5}, \mathrm{p}<0.00 \mathrm{I})$ during the study period. Anemia $(\mathrm{Hb}<120 \mathrm{~g} /$ L) was present in $131 / 349(37.5 \%, 95 \% \mathrm{Cl} 31.3,44.8)$ subjects at baseline, and in $70 / 363(19.3 \%, 95 \% \mathrm{Cl} 14.0,24.6)$ after twelve months. Iron deficiency reduced from $75 / 329(22.8 \%, 95 \% \mathrm{Cl} 16.9,28.6)$ to $33 / 353(9.3 \%, 95 \% \mathrm{Cl} 5.7,13.0)$ by the 12-mnth survey, and hookworm infection from $279 / 366(76.2 \%, 95 \% \mathrm{Cl} 68.6,83.8)$ to $66 / 287(23.0 \%, 95 \% \mathrm{Cl} 17.5$, 28.5) over the same period.

Conclusion: A free, universal WIFS program with regular deworming was associated with reduced prevalence and severity of anemia, iron deficiency and hookworm infection when made available to Vietnamese women over a I2-month period. 


\section{Background}

Anemia affects more than 1.5 billion people world-wide. Women are at particular risk, with $45.7 \%$ of non-pregnant women of reproductive age (WRA) in South-East Asia and $47.5 \%$ in Africa reported as anemic [1]. Anemia and the primary cause, iron deficiency, lead to reduced physical capacity, with consequences for both social and economic development [2]. Women who become pregnant while anemic due to insufficient iron stores are at higher risk of preterm delivery [3]. Maternal anemia is also linked with an increased risk of maternal death, impaired fetal growth, low birth weight and increased neonatal mortality [4-7]. Maternal iron deficiency anemia has been shown to be a predictor of iron deficiency in infants [8], which in turn is a risk factor for adverse physical and cognitive development in childhood $[9,10]$ and has implications for both maternal and infant mental health [11,12]. Low intake and poor absorption of dietary iron, and blood loss from menstruation and concurrent parasitic infections are major contributors to anemia and iron deficiency in women in less developed countries [7].

Food-based and supplementation strategies to improve iron status are recommended for populations at risk of anemia and iron deficiency [7]. Preventative weekly ironfolic acid supplementation (WIFS) for WRA is effective in improving iron stores [13-17] and has been advocated for widespread use in non-pregnant women in areas with high rates of maternal anemia [7]. This approach is supported by evidence that women with robust iron stores at the time of conception are less likely to develop iron deficiency anemia during pregnancy [18]. The current challenge is to develop implementation strategies and programmatic experience that can sustain universal longterm WIFS programs in resource-poor settings [19]. Vietnam initiated a daily iron supplementation program for pregnant women in 1993 [20]. Despite this, a survey undertaken in the central highlands of Vietnam in 2001 found that $62 \%$ of pregnant and $54 \%$ of non-pregnant women were anemic [21] following a trend in many countries that recommend similar regimens. We have previously reported $37.5 \%$ prevalence of anemia in nonpregnant women in northern Vietnam [22].

Following a baseline survey in November 2005 [22] we initiated a program that integrated distribution of universal WIFS and deworming into the existing health service structure in two districts of the northern mountainous province of Yen Bai, Vietnam, between May 2006 and April 2007. The program has subsequently been expanded to all districts of Yen Bai province. The broad aims were to identify the burden of anemia, iron deficiency, and soil transmitted helminth infections in non-pregnant WRA (reported in Pasricha et al 2008), and to investigate the impact of the WIFS/deworming intervention on hemoglobin (Hb), iron status indicators and hookworm preva- lence. In this paper we report the impact of 12 months implementation of the WIFS/deworming intervention and report the results of a compliance monitoring survey conducted after three months of the intervention.

\section{Methods \\ Study location and population}

Yen Bai province, one of 64 provinces and cities in Vietnam, is a mountainous region with a largely rural economy, widespread poverty and diverse ethnic groups. Two districts, Yen Binh and Tran Yen, were chosen for the study. At the time each district had a total population of approximately 26,000 WRA. Women of reproductive age were defined in this setting as aged between 15 and 45 years and all were eligible for the intervention.

\section{Intervention}

Before the intervention, two staff of each district Department of Preventive Medicine, two nurses from each commune health station and all village health workers in the two districts (a total of 680 health personnel) were trained about the causes, health risks, treatment and prevention of anemia and hookworm infection and received promotional and educational materials for the women. Commencing May 2006, weekly supplementation and 4 monthly deworming was implemented by active distribution through the existing health structure. Iron/folic acid and albendazole tablets were distributed from the provincial implementing agency, the Yen Bai Malaria Control Program office, through the district Preventive Medicine centres, to the Commune Health Stations (for albendazole treatment) and on to the Village Health Workers for distribution of the iron/folic acid tablets to the women on a monthly basis. In addition, health workers distributed simple educational materials. All WRA were encouraged to collect packs of four ferrous sulphate/folic acid tablets ( $60 \mathrm{mg} / 0.4 \mathrm{mg}$, UNICEF, Copenhagen) from their village health worker each month. Albendazole $(400 \mathrm{mg}$, UNICEF, Copenhagen) was administered as observed treatment on locally designated days either at the commune health station or supervised in the village by a commune health worker.

\section{Sampling}

A stratified multi-stage cluster sampling design was used for the baseline survey, which was conducted in November 2005. Primary sampling units (villages) were chosen using a 'probability proportional to size' random sampling method separately within each district, with half the target sample of villages taken from each district. Secondary sampling units (individual women) were selected randomly from each village using provincial lists. Sample size was calculated on an expected hemoglobin range of $90 \mathrm{~g} /$ $\mathrm{L}$ to $140 \mathrm{~g} / \mathrm{L}$ with a population standard deviation of $10 \mathrm{~g} /$ L. Allowing for the clustered nature of the surveys a sample size of 250 was estimated to be sufficient to detect a 3 
$\mathrm{g} / \mathrm{L}$ change in the mean hemoglobin. Allowing for refusals to participate and potentially inaccessible villages, 34 villages were selected and 12 women from each village randomly selected, a total of 408 women.

Post-implementation surveys were conducted after three and 12 months of intervention using the same sampling design for choosing participants. We used a cross sectional survey approach for participant selection at each time point in order to examine the population effect of the intervention in the target districts.

\section{Samples and testing}

All surveys were conducted by the same teams and included trained phlebotomists, stool preparation and analysis technicians, a demographic recorder and a supervisor. Sample collection and laboratory analysis has been previously reported [22] and was the same in each of the surveys. Briefly, $\mathrm{Hb}$ was assessed at the field site using a HemoCue 201+ (HemoCue AB, Angelholm, Sweden). A 3 $\mathrm{mL}$ sample of venous blood was also collected using a closed collection system into tubes containing fast clotting agent. Serum ferritin was measured using a sandwich immunoenzymatic assay (IEA; Beckman Coulter Access Reagents, Fullerton, CA). Soluble transferrin receptor was evaluated using enzyme-linked immunoassay (ELISA; IT; Orion Diagnostica, Espoo, Finland). The ratio of transferrin receptor to log (base 10) serum ferritin (TfR-F index) was calculated from these results. Anemia was defined as a hemoglobin concentration of $<120 \mathrm{~g} / \mathrm{L}$ and iron deficiency as serum ferritin of $<15 \mu \mathrm{g} / \mathrm{L}$, except where otherwise stated, in concordance with WHO recommendations for women of reproductive age [7]. Transferrin receptor levels of $2.3 \mathrm{mg} / \mathrm{L}$ or above were considered abnormal, based on the manufacturer's reference interval (0.8-2.3 $\mathrm{mg} / \mathrm{L}$ ). The TfR-F index implies depletion of iron stores once the ratio exceeds 1.8 [23].

Faecal samples were examined microscopically for soil transmitted helminth eggs at the field site using standard Kato-Katz methodology [24]. Classification of hookworm infection was based on WHO guidelines of 0 eggs per gram (epg) as no infection, $>0$ and $<2000$ epg as mild infection and $>2000$ as moderate or severe infection. Soil transmitted helminth (STH) infection was categorized as positive if eggs of hookworm (Ancylostoma duodenale and Necator americanus), Ascaris lumbricoides or Trichuris trichiura were detected in the stool sample.

\section{Compliance monitoring}

In July 2006, just prior to the 3-month post-implementation survey, the Research and Training Centre for Community Development (RTCCD), an independent Vietnamese non-Government Organization, monitored compliance in the two districts. Sampling was as described for the surveys above. Monitoring was conducted as one-to-one interviews with women and included questions about their understanding of anemia, iron deficiency and helminthiasis, the availability of the intervention and their recall of accessing the deworming treatment and taking the weekly iron tablets during the previous 10 weeks.

\section{Data entry and checking}

$\mathrm{Hb}$ and helminth egg counts were entered into an Excel (Microsoft Office 2003) spreadsheet at the field site. Team supervisors crosschecked entries each day.

\section{Statistical analysis}

The study sample was defined as randomly selected groups at baseline and three and twelve months postimplementation. Hb values were approximately normally distributed. Serum ferritin and soluble transferrin receptor values were right-skewed and so log-transformed for analysis. For certain multi-level ordered categorical variables (e.g. education level, place of work), some categories were collapsed to identify relevant differences. Robust confidence intervals were derived by clustering for village, the primary sampling unit.

Linear regression analysis was used for continuous variables while binary variables were analysed by logistic regression. For continuous variables the differences in means between time points were calculated in absolute values for $\mathrm{Hb}$, and for the log transformed variables (serum ferritin, soluble transferrin receptor and the TfR/FIndex) as the ratio of the geometric means between postimplementation and baseline surveys. Binary prevalence variables were analysed by proportion estimation adjusted for robust SEs with clusters as villages. Change over time was analysed as the risk ratio between postimplementation and baseline. Statistical analysis was performed using Stata vs. 10 (StataCorp, 2005, College Station, Texas).

\section{Ethics}

Extensive consultation was undertaken between the project team and community leaders, as well as liaison with village, district and provincial health staff. Village health workers provided participants with information regarding the surveys and signed informed consent was documented at the time of enrolment for the surveys. The survey team assisted the village health workers where participants expressed concerns or uncertainty relating to any aspect of their participation. The project was approved by the Human Research Ethics Committee of the National Institute of Malariology, Parasitology and Entomology (Hanoi, Vietnam), the Walter and Eliza Hall Institute of Medical Research (Melbourne, Australia) and Melbourne Health (Melbourne, Australia). 


\section{Results}

Three hundred and eighty-two women participated in the baseline survey, and 338 and 364 women attended the 3month and 12-month post-implementation surveys respectively. Details of the study design and number of women enrolled in each survey are shown in Figure 1, and baseline demographic data are shown in Table 1. Altogether, 349/382 women had $\mathrm{Hb}$ measured at baseline, $335 / 338$ in the three month and 363/364 in the 12 month survey. Figure 2 shows the $\mathrm{Hb}$ means and 95\% confidence intervals at each survey point. The prevalence of anemia at baseline was $37.5 \%(131 / 349)$, (95\% CI 31.3, 44.8), at three months post-intervention $28.4 \%(94 / 335)(24 \%$ reduction, RR $0.76,95 \%$ CI $0.58,0.98, \mathrm{p}=0.036$ ) and $19.3 \%(70 / 363)$ at 12 months post-implementation, a reduction on baseline prevalence of $49 \%$ (RR $0.51,95 \%$ CI $0.37,0.71, \mathrm{p}<0.001)$. The prevalence of mild anemia $\left(\mathrm{Hb}^{*}<120 \mathrm{~g} / \mathrm{L} \&>=100 \mathrm{~g} / \mathrm{L}\right)$ and moderate/severe anemia, $(\mathrm{Hb}<100 \mathrm{~g} / \mathrm{L})$ at baseline, three and 12 months postimplementation is shown in Figure 3.

Geometric means for serum ferritin, soluble transferrin receptor and the TfR/F-Index are shown in Table 2. The serum ferritin geometric means and 95\% CI are shown in Figure 4, mapped to a log scale. The prevalence of iron deficiency anemia at baseline was 14.0\% (46/329) (95\% CI, 10.2, 17.7). Three months post-implementation it had reduced to $5.9 \%(19 / 320)$ a reduction of $57 \%$ (RR 0.43 , $95 \%$ CI $0.26,0.70, \mathrm{p}=0.001$ ) and at twelve months postintervention was $4.5 \%(16 / 353)$ or $78 \%$ less than baseline (RR $0.32,95 \%$ CI $0.15,0.68, \mathrm{p}=0.003$ ). Prevalence of iron deficiency with or without anemia was $22.8 \%$ (75/ $329)(95 \%$ CI $16.9,28.6)$. By three months post-implementation this had reduced to $10.9 \%(35 / 320)$, a $52 \%$ reduction in prevalence (RR $0.48,95 \%$ CI $0.34,0.69$, p < 0.001 ) followed by a further small reduction to $59 \%$ of baseline (RR $0.41,0.26,0.64, \mathrm{p}<0.001$ ), a prevalence of $9.3 \%(33 / 353)$.

The prevalence of hookworm infection by severity at baseline and at the 3-and 12-month post-implementation surveys is shown in Table 3. Overall prevalence of hookworm infection at baseline was $76.2 \%(279 / 366)$. At the three month post-implementation survey overall prevalence was $56.3 \%(126 / 224)$, a $26 \%$ reduction (RR 0.74 , $95 \%$ CI $0.62,0.89, \mathrm{p}<0.001)$ and at 12 months $23.0 \%$

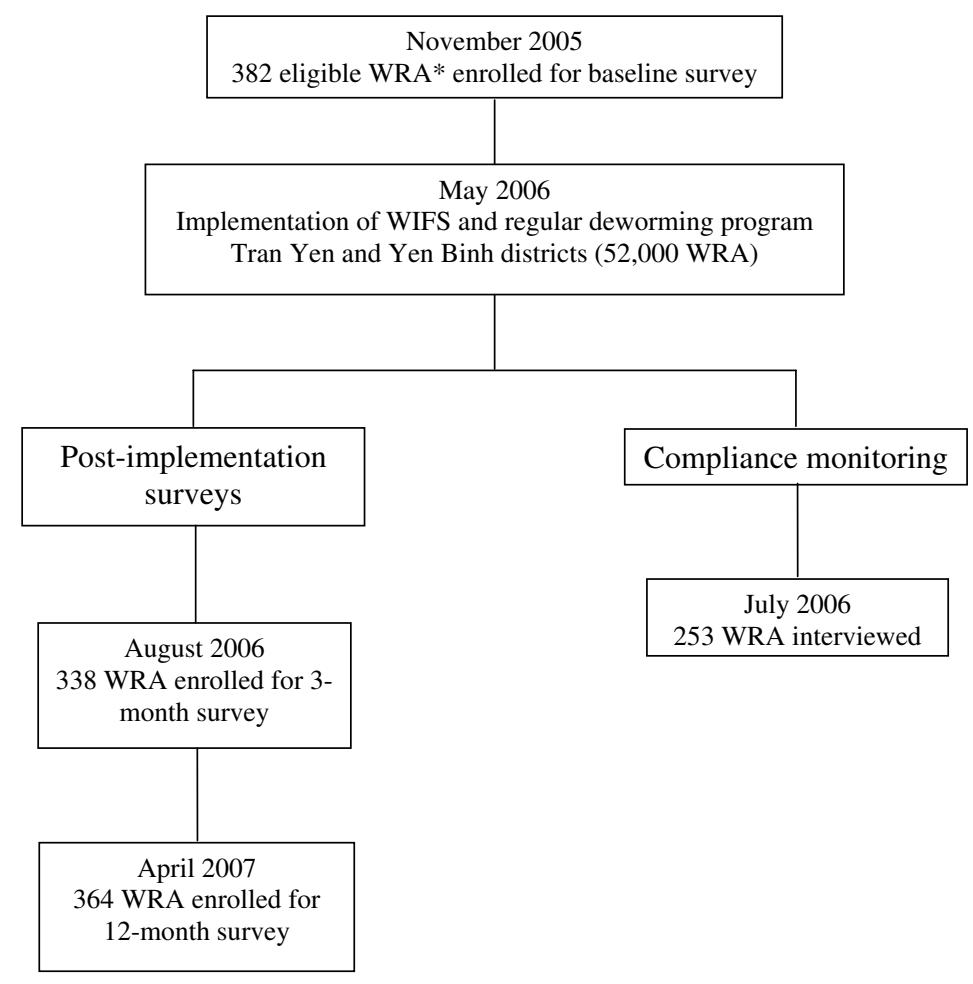

Figure I

Flow diagram of evaluation of WIFS \# and 4 monthly deworming program: baseline, 3- and I 2-months postimplementation. \#WIFS = Weekly Iron-Folic acid Supplementation * WRA = Women of Reproductive Age defined as aged between $15-45$ years. 


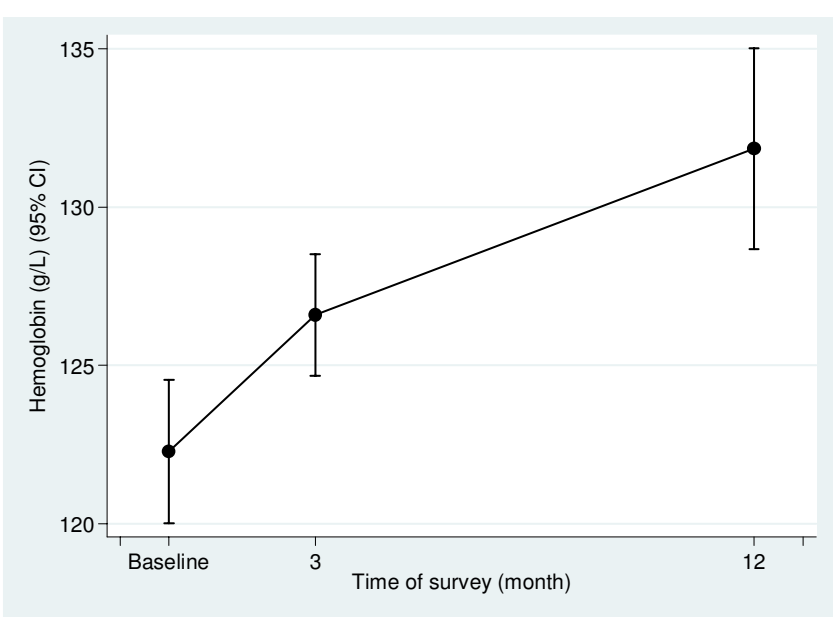

Figure 2

Mean hemoglobin $(95 \% \mathrm{Cl})$ at baseline, 3- and I2months post-implementation.

representing a $70.0 \%$ reduction in prevalence ( $R R$ 0.30, $95 \%$ CI $0.24,0.39, \mathrm{p}<0.001)$. The prevalence of any STH infection was $83.5 \%(95 \%$ CI $77.6,89.5)$ at baseline, $64.3 \%(95 \%$ CI 55.7, 72.8) at three months and 32.7 (95\% CI 25.0, 38.4) at twelve months post-implementation. Risk ratios for the change in prevalence of any soil transmitted infection at three- and twelve-months postimplementation were 0.77 (95\% CI, 0.66, 0.89, p < $0.001)$ and 0.38 (95\% CI, 0.30, 0.47, p < 0.001) respectively.

To assess compliance, the independent monitor interviewed 253 women of whom 251 had received at least some iron tablets. On a ten week recall, and supported by counting remaining tablets in the women's homes, two women reported not taking any iron tablets and 202/249 $(71.1 \%)$ reported taking 6 or more tablets. High compliance was associated with literacy and education levels, $73 \%(154 / 211)$ of literate women reported high compli-

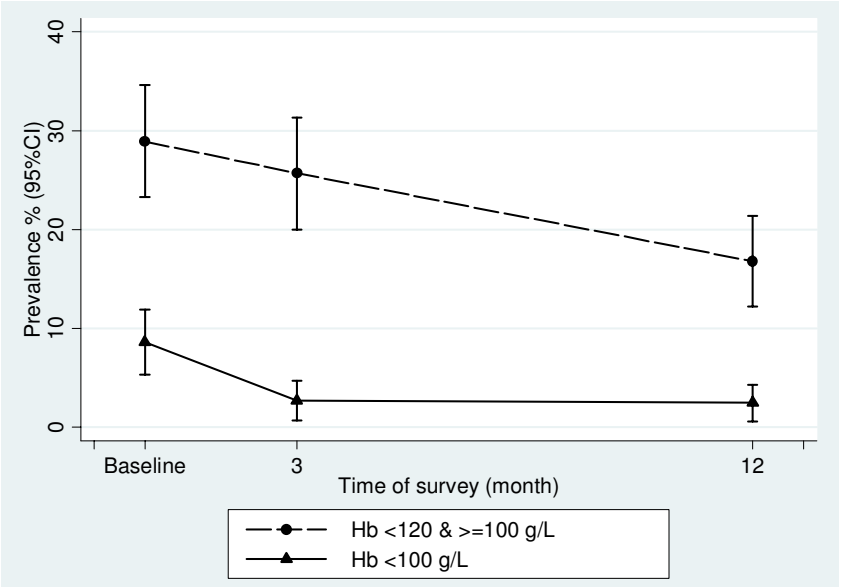

Figure 3

Prevalence of mild ( $\left.\mathrm{Hb}^{*}<120 \mathrm{~g} / \mathrm{L} \&>=100 \mathrm{~g} / \mathrm{L}\right)$ and moderate/severe anemia ( $\mathrm{Hb}<100 \mathrm{~g} / \mathrm{L})$, with $95 \% \mathrm{Cl}$ at each survey. $* \mathrm{Hb}=$ hemoglobin.

ance compared with 50\% (15/30) of illiterate women. For the deworming compliance, 225/241 (93.4\%) of nonpregnant women received the albendazole and 217/225 $(96.4 \%)$ of women receiving tablets reported taking it.

\section{Discussion}

We have successfully integrated a large-scale, universal WIFS and deworming program into an existing public health structure. The program was distributed free of charge by village health workers to all women of reproductive age in the study districts. The post-implementation surveys showed an ongoing reduction in the prevalence and severity of anemia and hookworm infection over a twelve-month period. The independent monitor's report on the effectiveness of the distribution system and women's compliance supports the premise that the WIFS and regular deworming program was the principle reason for these improvements.

Table I: Demographic characteristics of women participating in the baseline survey in November 2005.

\begin{tabular}{lll}
\hline Demographic & Number of respondents & Mean \pm SD or frequency (\%) \\
\hline Age (years) & 382 & $30.1 \pm 7.9$ \\
Number of children & 378 & $1.7 \pm 1.1$ \\
Education finished & 375 & \\
$\quad$ None/Primary (Grades I-5) & & $84(22.4)$ \\
Secondary (Grades 6-9) & & $211(56.3)$ \\
High (Grades I0-I2)/Post-secondary & 369 & $80(21.3)$ \\
Meat consumption (meals/week) & 372 & $4.0 \pm 2.9$ \\
Outdoor work (vs. indoor work) & 352 & $317(85.2)$ \\
Time since previous deworming & & $50(14.2)$ \\
$\quad$ I wk-I2 months & & $160(45.5)$ \\
I year to <10 years & & $142(40.3)$ \\
$\geq$ I0 years/never & &
\end{tabular}




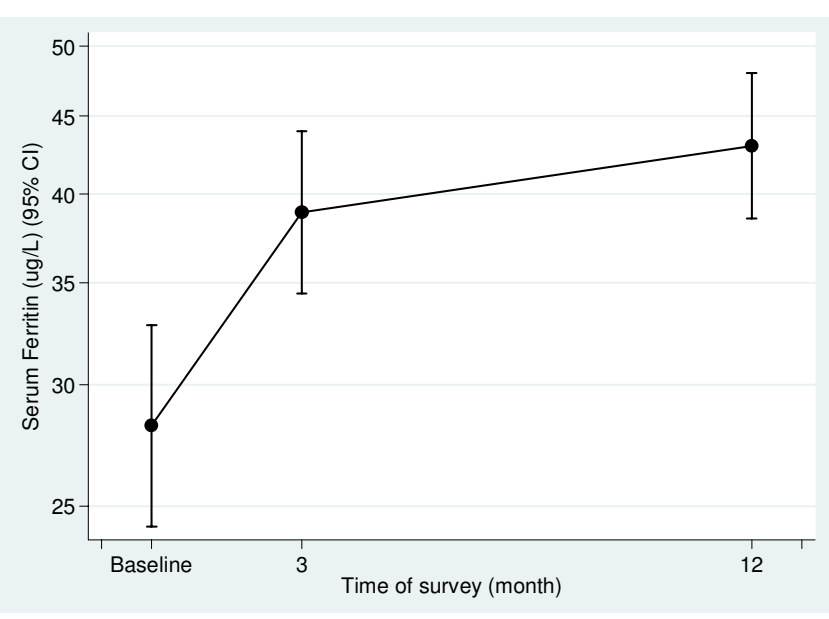

Figure 4

Geometric mean serum ferritin $(95 \% \mathrm{CI})$ at baseline, 3- and I 2-months post-implementation.

The strength of our approach was that distribution was easily integrated into existing health services and was made freely available to all women, regardless of socioeconomic or marital status. This was accompanied by nutritional education for communities and their health workers. This meant that the benefits of iron sufficiency were available for all women in their childbearing years, and their enthusiasm for the program was shown by the continued improvement in iron status and worm infection prevalence over twelve months, suggesting high compliance. The program was viewed as practical and effective by all levels of the health sector and the community and has now been expanded to every district in Yen Bai province.

The main limitation to the study was the absence of a control group. This would have allowed us to establish the prevalence of anemia and iron deficiency based on the proportion of women who responded to iron supplementation/deworming compared with those receiving placebo, and to be able to attribute response to the intervention. However, the main objective of the study was to conduct a large demonstration project using WIFS/ deworming as an established strategy for reducing anemia and iron deficiency amongst women in developing coun- tries, and we did not feel it ethical to include a control arm in which women were not treated for anemia and STH infections.

The residual anemia prevalence of $19.5 \%$ may be mainly explained by causes of anemia other than iron deficiency, such as genetic hemoglobinopathies, which are found amongst certain populations in South East Asia $[25,26]$. It has been estimated that in the WHO Western Pacific Region less than four percent of the population carry a $\mathrm{Hb}$ disorder [27] while a later study of schoolchildren in a different province of northern Vietnam found the prevalence of hemoglobinopathy (reporting totaled figures for HbA2, HbAE and HbF, others not tested for) to range between 3.8 and $9.3 \%$ [28]. Malaria is unlikely to have been a cause of anemia in the target population as it has been largely eliminated from the province, with only two imported cases reported in 2005 (Dr. L. B. Phu, Director Malaria Control Program, Yen Bai, Personal Communication). Compliance monitoring suggested that noncompliance was uncommon in the study group. However, to maintain high compliance we developed new training, educational and promotional materials for health workers and women following the 3-month compliance survey, as it showed that low and non-compliance with taking the weekly iron/folic acid supplement was associated with low education levels.

There have been few WIFS/multi-micronutrient programs successfully maintained for 12 months or more and most have targeted pregnant women $[29,30]$ and/or adolescent schoolgirls and small children [29,31]. A WHO-sponsored program in three South-east Asian countries provided free daily iron supplements for pregnant women and encouraged non-pregnant women to purchase weekly iron supplements [15]. Extensive social marketing was undertaken within the targeted communities. In Vietnam, mean $\mathrm{Hb}$ levels increased by $6.0 \mathrm{~g} / \mathrm{L}$ in a cohort of nonpregnant women tested four times over twelve months [32]. In Cambodia increases in Hb levels were associated with higher socio-economic status in groups of schoolgirls, garment factory workers and rural women [33], and in the Philippines there was a significant increase in serum ferritin but minimal change in $\mathrm{Hb}$ [34]. Dwivedi et al (2006) reported a Government-sponsored community-

Table 2: Comparisons of iron status markers at baseline and 3- and I 2-months post-implementation.

\begin{tabular}{lrrrrrrrrr}
\hline \multicolumn{1}{l}{ Survey } & \multicolumn{3}{c}{ Serum ferritin $\mu g / L^{*}$} & \multicolumn{3}{c}{ Soluble Transferrin Receptor $\mathrm{mg} / \mathrm{L}^{*}$} & \multicolumn{2}{c}{ TfR/Fe-Index* } \\
\hline & $\mathrm{n}$ & Mean & $95 \% \mathrm{Cl}$ & $\mathrm{n}$ & Mean & $95 \% \mathrm{Cl}$ & $\mathrm{n}$ & $\mathrm{Mean}$ & $95 \% \mathrm{Cl}$ \\
Baseline & 329 & 28.2 & $(24.2,32.9)$ & 336 & 1.69 & $(1.60,1.78)$ & 326 & 1.24 & $(1.05,1.14)$ \\
3 month & 320 & 38.9 & $(34.4,44.0)$ & 329 & 1.71 & $(1.63,1.80)$ & 320 & 1.10 & $(1.01,1.07)$ \\
12 month & 353 & 43.2 & $(38.6,48.0)$ & 361 & 1.41 & $(1.34,1.48)$ & 352 & 0.95 & $(0.92,0.98)$ \\
\hline
\end{tabular}

* Exponentiated means and $95 \% \mathrm{Cls}$ of log transformed values, $\mathrm{SE}$ adjusted for clusters as village. 
Table 3: Comparisons of prevalence of hookworm infection severity at baseline and 3- and I 2-months post-implementation.

\begin{tabular}{|c|c|c|c|c|c|c|c|}
\hline \multirow{3}{*}{ Survey } & & \multicolumn{6}{|c|}{ Hookworm } \\
\hline & & \multicolumn{2}{|c|}{ No infection* } & \multicolumn{2}{|c|}{ Mild infection* (<2000 epg*) } & \multicolumn{2}{|c|}{ Moderate/severe* infection $(>=2000$ epg) } \\
\hline & $\mathrm{n}$ & Percent & $95 \% \mathrm{Cl}$ & Percent & $95 \% \mathrm{Cl}$ & Percent & $95 \% \mathrm{Cl}$ \\
\hline Baseline & 366 & 23.8 & $16.4,31.1$ & 60.1 & $54.1,66.1$ & 16.1 & II.3, 20.9 \\
\hline 3-month & 224 & 43.2 & $34.8,52.7$ & 54.5 & $45.5,63.4$ & 1.8 & $0.04,3.5$ \\
\hline I2-month & 295 & 77.0 & $71.5,82.5$ & 21.6 & $16.2,26.9$ & 1.4 & $0.1,2.6$ \\
\hline
\end{tabular}

epg = eggs per gram

* Proportion estimation by survey, SE adjusted for clusters as village

based WIFS program targeted at adolescent girls in 13 Indian states. A cross-sectional survey after 12 months showed a reduction in anemia prevalence ranging from $5 \%$ to $50 \%$ and, in one of the Indian states, a $70 \%$ reduction after two years of supplementation.

\section{Conclusion}

In conclusion, our results show that free, universal WIFS with regular deworming was associated with a reduced prevalence and severity of anemia and hookworm infection in non-pregnant women over a 12 -month period. The equitable, universal nature of the program and the endorsement and involvement of the health sector from provincial to village level were major factors in its ongoing success. Countries with high rates of anemia in women should urgently consider WIFS and regular deworming as interim measures until sustainable alternatives are implemented and shown to be effective $[35,36]$.

\section{Competing interests}

The authors declare that they have no competing interests.

\section{Authors' contributions}

GC, TP, AM and BAB developed the project protocol, GC and $\mathrm{BAB}$ provided project management, GC, TP, and NT coordinated the project, TT coordinated the RTCCD surveys, GC and TP were responsible for managing the study teams, collecting data and data entry. GC, SM and LM assisted with data analysis. All authors reviewed and approved the final manuscript.

\section{Acknowledgements}

The authors acknowledge the support of Yen Bai People's Committee, district and commune health staff, and village health workers. We are grateful to the staff of the local implementing agency, Yen Bai Malaria Control Centre, to Dr. Cavalli-Sforza who provided valuable suggestions, Pham Thi Xuyen, Beth Hilton-Thorp and Christalla Hajisava for invaluable contributions. We are especially thankful to Prof. Damien Jolley for assistance with design and the analysis strategy. Most importantly, we thank the women of Tran Yen and Yen Binh who participated in these surveys. Atlantic Philanthropy (USA) Incorporated kindly funded the project.

\section{References}

I. World Health Organization: Worldwide prevalence of anaemia 1993-2005; WHO global database on anaemia. Geneva 2008.
2. Horton S, Ross J: The economics of iron deficiency. Food Policy 2003, 28(I):5I-75.

3. Scholl TO, Hediger ML, Fischer RL, Shearer JW: Anemia vs iron deficiency: increased risk of preterm delivery in a prospective study. Am J Clin Nutr 1992, 55(5):985-988.

4. Allen LH: Anemia and iron deficiency: effects on pregnancy outcome. Am J Clin Nutr 2000, 7 I (5 Suppl): I280S- I284S

5. Hindmarsh PC, Geary MP, Rodeck CH, Jackson MR, Kingdom JC: Effect of early maternal iron stores on placental weight and structure. Lancet 2000, 356(923I):7I9-723.

6. Kadyrov M, Kosanke G, Kingdom J, Kaufmann P: Increased fetoplacental angiogenesis during first trimester in anaemic women. Lancet 1998, 352(9 | 42): 1747-1749.

7. WHO: Iron Deficiency Anaemia - Assessment, Prevention and Control. A guide for programme managers. In $\mathrm{WHO}$ NHD/0 I.3 Geneva: World Health Organisation; 200 I:I-I I 4.

8. Preziosi P, Prual A, Galan P, Daouda H, Boureima H, Hercberg S: Effect of iron supplementation on the iron status of pregnant women: consequences for newborns. Am J Clin Nutr 1997, 66(5): $1178-1182$.

9. Allen LH, Gillespie SR: What Works? A Review of the Efficacy and Effectiveness of Nutrition Interventions. In The Asian Development Bank Nutrition and Development Series Edited by: ACC/ SCN. Geneva in collaboration with the Asian Development Bank, Manila: ACC/SCN; 2001.

10. Walker SP, Wachs TD, Gardner JM, Lozoff B, Wasserman GA, Pollitt E, Carter JA: Child development: risk factors for adverse outcomes in developing countries. Lancet 2007, 369(9556): $145-157$

II. Murray-Kolb LE, Beard JL: Iron deficiency and child and maternal health. Am J Clin Nutr 2009, 89(3):946S-950.

12. Wachs TD: Models linking nutritional deficiencies to maternal and child mental health. Am J Clin Nutr 2009, 89(3):935S-939.

13. Angeles-Agdeppa I, Schultink W, Sastroamidjojo S, Gross R, Karyadi $D$ : Weekly micronutrient supplementation to build iron stores in female Indonesian adolescents. Am J Clin Nutr 1997, 66(I): $177-183$.

14. Berger J, Aguayo VM, Tellez W, Lujan C, Traissac P, San Miguel JL: Weekly iron supplementation is as effective as 5 day per week iron supplementation in Bolivian school children living at high altitude. European journal of clinical nutrition 1997, 5 I (6):38I-386.

15. Cavalli-Sforza T, Berger J, Smitasiri S, Viteri F: Weekly iron-folic acid supplementation of women of reproductive age: impact overview, lessons learned, expansion plans, and contributions toward achievement of the millennium development goals. Nutr Rev 2005, 63(12 Pt 2):SI52-I58.

16. Tee ES, Kandiah M, Awin N, Chong S-M, Satgunasingam N, Kamarudin L, Milani S, Dugdale AE, Viteri FE: School-administered weekly iron-folate supplements improve hemoglobin and ferritin concentrations in Malaysian adolescent girls. Am J Clin Nutr 1999, 69(6): 1249-1256.

17. Viteri FE: Iron supplementation as a strategy for the control of iron deficiency and ferropenic anemia. Archivos latinoamericanos de nutricion 1999, 49(3 Suppl 2): I5S-22S.

18. Milman N: Prepartum anaemia: prevention and treatment. Annals of hematology 2008, 87( I 2):949-959.

19. Horton R: Maternal and child undernutrition: an urgent opportunity. Lancet 2008, 37 I(9608): 179. 
20. Khan NC, Thanh HT, Berger J, Hoa PT, Quang ND, Smitasiri S, Cavalli-Sforza T: Community mobilization and social marketing to promote weekly iron-folic acid supplementation: a new approach toward controlling anemia among women of reproductive age in Vietnam. Nutr Rev 2005, 63(12 Pt 2):S87-94

21. Trinh LT, Dibley M: Anaemia in pregnant, postpartum and non pregnant women in Lak district, Daklak province of Vietnam. Asia Pacific journal of clinical nutrition 2007, 16(2):310-3I5.

22. Pasricha SR, Caruana SR, Phuc TQ, Casey GJ, Jolley D, Kingsland S, Tien NT, MacGregor L, Montresor A, Biggs BA: Anemia, iron deficiency, meat consumption, and hookworm infection in women of reproductive age in northwest Vietnam. Am J Trop Med Hyg 2008, 78(3):375-38I.

23. Suominen P, Punnonen K, Rajamaki A, Irjala K: Serum transferrin receptor and transferrin receptor-ferritin index identify healthy subjects with subclinical iron feficits. Blood 1998 92(8):2934-2939.

24. Ash LR, Orihel TC, Savioli L, Sin MA, Montresor A, Renganathan E: Training manual on diagnosis of intestinal parasites - tutor's guide Geneva: World Health Organization; 2004.

25. Carnley BP, Prior JF, Gilbert A, Lim E, Devenish R, Sing H, Sarin E, Guhadasan R, Sullivan SG, Wise CA, et al: The prevalence and molecular basis of hemoglobinopathies in Cambodia. Hemoglobin 2006, 30(4):463-470.

26. Svasti ML, Hieu TM, Munkongdee T, Winichagoon P, Van Be T, Van Binh T, Fucharoen S: Molecular analysis of beta-thalassemia in South Vietnam. American journal of hematology 2002, 7 I(2):85-88

27. Angastiniotis M, Modell B: Global Epidemiology of Hemoglobin Disorders. Annals of the New York Academy of Sciences 1998, 850(COOLEY'S ANEMIA: SEVENTH SYMPOSIUM):25I-269.

28. Le HT, Brouwer ID, Nguyen KC, Burema J, Kok F): The effect of iron fortification and de-worming on anaemia and iron status of Vietnamese schoolchildren. British Journal of Nutrition 2007, 97(5):955-962.

29. Christian P, Shrestha J, LeClerq SC, Khatry SK, Jiang T, Wagner T, Katz J, West KP Jr: Supplementation with micronutrients in addition to iron and folic acid does not further improve the hematologic status of pregnant women in rural Nepal. The Journal of nutrition 2003, I33(II):3492-3498.

30. Sharma JB, Jain S, Mallika V, Singh T, Kumar A, Arora R, Murthy NS A prospective, partially randomized study of pregnancy outcomes and hematologic responses to oral and intramuscular iron treatment in moderately anemic pregnant women. Am J Clin Nutr 2004, 79(I): I I6-122.

31. Dwivedi A, Schultink W: Reducing anaemia among Indian adolescent girls through once weekly supplementation with iron and folic acid. SCN News 2006, 3 I (Late 2005 - Early 2006): 19-23.

32. Berger J, Thanh HT, Cavalli-Sforza T, Smitasiri S, Khan NC, Milani S, Hoa PT, Quang ND, Viteri F: Community mobilization and social marketing to promote weekly iron-folic acid supplementation in women of reproductive age in Vietnam: impact on anemia and iron status. Nutr Rev 2005, 63(1 2 Pt 2):S95-108

33. Crape BL, Kenefick E, Cavalli-Sforza T, Busch-Hallen J, Milani S, Kana K: Positive Impact of a Weekly Iron-Folic Acid Supplement Delivered with Social Marketing to Cambodian Women: Compliance, Participation, and Hemoglobin Levels Increase with Higher Socioeconomic Status. Nutrition Reviews 2005, 63:SI34-SI38

34. Angeles-Agdeppa I, Paulino LS, Ramos AC, Etorma UM, Cavalli-Sforza T, Milani S: Government-Industry Partnership in Weekly IronFolic Acid Supplementation for Women of Reproductive Age in the Philippines: Impact on Iron Status. Nutrition Reviews 2005, 63:SII6-SI25.

35. Pena-Rosas IP, Viteri FE: Effects of routine oral iron supplementation with or without folic acid for women during pregnancy. Cochrane Database Syst Rev 2006, 3:CD004736.

36. WHO: Weekly iron-folic acid supplementation (WIFS) in women of reproductive age: its role in promoting optimal maternal and child health. Position statement. Geneva: World Health Organization; 2009.

\section{Pre-publication history}

The pre-publication history for this paper can be accessed here:

http://www.biomedcentral.com/1471-2458/9/261/pre pub
Publish with Biomed Central and every scientist can read your work free of charge

"BioMed Central will be the most significant development for disseminating the results of biomedical research in our lifetime. "

Sir Paul Nurse, Cancer Research UK

Your research papers will be:

- available free of charge to the entire biomedical community

- peer reviewed and published immediately upon acceptance

- cited in PubMed and archived on PubMed Central

- yours - you keep the copyright
BioMedcentral 